\title{
Gallbladder function predicts subsequent biliary complications in patients with common bile duct stones after endoscopic treatment?
}

Tzung-Jiun Tsai ${ }^{1}$ (D), Hoi-Hung Chan ${ }^{1,2,4,5,6^{*}}$, Kwok-Hung Lai ${ }^{1,2}$, Chih-An Shih', Sung-Shuo Kao ${ }^{1,2}$, Wei-Chih Sun ${ }^{1}$, E-Ming Wang ${ }^{1}$, Wei-Lun Tsai ${ }^{1,2}$, Kung-Hung Lin ${ }^{1}$, Hsien-Chung Yư ${ }^{1}$, Wen-Chi Chen ${ }^{1,2}$, Huay-Min Wang ${ }^{1}$,

Feng-Woei Tsay ${ }^{1}$, Huey-Shyan Lin ${ }^{3}$, Jin-Shiung Cheng ${ }^{1}$ and Ping-I Hsu, ${ }^{1,2}$

\begin{abstract}
s
Background: In patients with common bile duct stones (CBDS) and intact gallbladder, further management for the gallbladder after the CBDS clearance is still controversial. The relationship between gallbladder motility and the biliary complications were seldom discussed. Our study is to predict the subsequent biliary complications by gallbladder function test using fatty meal sonography (FMS) in patients with CBDS who had been treated by endoscopic retrograde cholangiopancreatography (ERCP).

Methods: Patients with an intact gallbladder and CBDS after endoscopic clearance of bile duct were enrolled. Patients received a fatty meal sonography after liver function returned to normal. The fasting volume, residual volume, and gallbladder ejection fraction (GBEF) in FMS were measured. Relationships of patients' characteristics, gallbladder function and recurrent biliary complication were analyzed.
\end{abstract}

Results: From 2011 to 2014, 118 patients were enrolled; 86 patients had calculus gallbladders, and 32 patients had acalculous gallbladders. After a mean follow- up of 33 months, 23 patients had recurrent biliary complications. Among 86 patients with calculus gallbladder, 15 patients had spontaneous clearance of gallbladder stones; 14 patients received cholecystectomy due to acute cholecystitis or recurrent colic pain with smooth postoperative courses. In the follow up period, six patients died of non-biliary causes. The GBEF is significant reduced in most patients with a calculus gallbladder in spite of stone color. Calculus gallbladder, alcohol drinking and more than one sessions of initial endoscopic treatment were found to be the risk factors of recurrent biliary complication.

Conclusions: Gallbladder motility function was poorer in patients with a calculus gallbladder, but it cannot predict the recurrent biliary complication. Since spontaneous clearance of gallbladder stone may occur, wait and see policy of gallbladder management after endoscopic treatment of CBDS is appropriate, but regular follow- up in those patients with risk factors for recurrence is necessary.

Keywords: Endoscopic retrograde cholangiopancreatography, Gallbladder dyskinesia, Gallstones, Recurrent biliary complications

\footnotetext{
* Correspondence: hoihungchan@gmail.com

${ }^{1}$ Division of Gastroenterology and Hepatology, Department of Internal

Medicine, Kaohsiung Veterans General Hospital, Kaohsiung, Taiwan, Republic

of China

${ }^{2}$ School of Medicine, National Yang-Ming University, Taipei, Taiwan, Republic

of China

Full list of author information is available at the end of the article
} 


\section{Background}

Endoscopic sphincterotomy (EST), endoscopic papillary balloon dilation (EPBD), and endoscopic papillary large balloon dilation (EPLBD) are commonly used methods to enlarge the biliary orifice and remove common bile duct stones (CBDS) [1, 2]. In patients with CBDS and an intact gallbladder, the management of the gallbladder after endoscopic clearance of the bile duct is controversial. Some studies suggest that elective cholecystectomy after endoscopic clearance of CBDS may reduce the late biliary complications [3-5], but other studies have not confirmed the same benefits [6-8]. Tsujino et al. found that patients either with cholecystectomy before EPBD or with a calculus gallbladder had higher rate of CBDS recurrence than those with elective cholecystectomy after EPBD or an acalculous gallbladder (10.8\% and $15.6 \%$ vs. $2.4 \%$ and $5.9 \%$, respectively) [9]. In our previous study, patients with calculus gallbladder exhibited a higher incidence of an overall delayed biliary complications than those with acalculous gallbladder and cholecystectomy both before and after endoscopic treatment for CBDS. However, the incidence of recurrent CBDS in patients with calculus gallbladder was similar to that in the cholecystectomized patients, but higher than in patients with acalculous gallbladder [10]. Since slow biliary emptying contribute to recurrent CBDS even after endoscopic sphincterotomy [11], the gall bladder left in situ may be able to wash away bile and prevent recurrence or flush out newly produced stones [12]. Although the filling and emptying of the gallbladder may be impaired in patients with gallstones [13], improved gallbladder emptying and reduced lithogenicity of bile have been reported after endoscopic sphincterotomy $[14,15]$. Sugiyama et al. found that EPBD did not affect gallbladder motility in the long-term (five years) [16]. However, the relationship between gallbladder status, motility and recurrent biliary complications after endoscopic treatment has seldom been discussed.

The aim of our study is to evaluate the gallbladder function and outcome of patients with CBDS and an intact gallbladder after endoscopic clearance of the bile duct, and to evaluate the relationship between the gallbladder motility, gallstone status, and other factors that affect the recurrence of biliary complications.

\section{Methods}

This study was approved by the Institutional Review Board of Kaohsiung Veterans General Hospital and was performed according to the Helsinski Declaration. The protocol was registered in the Government Research Bulletin according to the law of Taiwan. Informed written consent was obtained from all participants in this study.

\section{Patients}

Patients with an intact gallbladder and CBDS, including patients with biliary pancreatitis, who had received endoscopic clearance of bile duct and refused for elective cholecystectomy, were enrolled. Patients who had recurrent CBDS, association with intrahepatic stones or malignant diseases, first detected recurrent biliary complication during the follow-up period (within six months) after clearance of bile duct, elective cholecystectomy subsequently for nonbiliary cause, or refusals of follow-up were excluded.

\section{Endoscopic treatment}

All the endoscopic treatments were performed under local anesthesia of the pharynx with $10 \%$ xylocaine, intramuscular injection with $40 \mathrm{mg}$ hyosine-N butybromide and 25-50 mg meperidine were administered as premedication. Endoscopic retrograde cholangiopancreatography (ERCP) was performed in the standard manner using a side-view endoscope (JF240, JF260; Olympus Optical Corporation, Tokyo, Japan). End-view endoscope (GIF1T, GIFXQ, Olympus Optical Corporation, Tokyo, Japan) was used in patient with prior Billroth II gastrectomy. Endoscopic large balloon dilation (CRE balloon $5.5 \mathrm{~cm}$ in length,1-1.2 cm/1.2-1.5 cm/1.5-2.0 cm in diameter; Boston Scientific Corp, Ireland) usually performed to enlarge the papillary orifice. Using fluoroscopic and endoscopic guidance, the balloon was inflated with diluted contrast solution up to the optimal size for 2-6 min according to the patients' condition and tolerance. In order to minimize the risk of perforation, the size of balloon should not be exceeded the diameter of the CBD [17]. In the patients with difficult deep cannulation, precut followed by full sphincterotomy using needle knife sphincterotome(KD-V451 M, Olympus Co. Japan) and conventional sphincterotome (Truetome 39, Boston Scientific Crop, Ireland) were performed. After enlargement of papillary orifice, the CBDS were retrieved by basket (FG V22PR, FGV21PR, Olympus Co. Japan) until completely clearance of bile duct. If the stones were larger than the distal bile duct, they were fragmented by lithotripter (BML-V232QR-30, Olympus Co. Japan) before extraction.

\section{Stone color stratification}

According to natural history of gallstones and CBD stones, we classified the stones into primary and secondary CBD stone according to the stone color $[18,19]$. The secondary CBD stone were white cholesterol or black pigment stone, which forms primary in gallbladder and secondary migrate into CBD. The primary stone was brown pigment stone, which usually forms primary in CBD.

\section{Follow-up studies}

Patients were followed in a special clinic every two weeks soon after discharge. Patients received a fatty meal 
sonography (FMS) to evaluate the gallbladder function when their liver function returned to normal. Patients were then scheduled for follow-up visits every three months. During each visit, a blood sample was taken for liver function test every three months. Abdominal sonogram was performed every six months or at the time of abnormal liver function test or clinical symptoms suggesting recurrent biliary complications. Further image study, such as CT scan, magnetic resonance cholangiopancreatography (MRCP) or ERCP would be performed if recurring biliary symptoms, abnormal liver function test, or abdominal sonography suggested recurrent stones. Cholecystectomy would be advised if biliary symptoms indicated cholecystitis.

\section{Fatty meal sonography}

After fasting for eight hours, routine abdominal sonography was performed to measure the fasting gallbladder volume. The volume of gallbladder was measured by the ellipsoid method as described by Dodds et al. [20]. A fatty meal with two fried eggs and $250 \mathrm{~mL}$ of full milk (fat 28 g,protein $22 \mathrm{~g}$, carbohydrate $12 \mathrm{~g}$, total $388 \mathrm{Kcal}$ ) was taken by the patients after measurement of fasting gallbladder volume [21]. Repeated gallbladder volume measurement every 15 min until 90 min were done after the intake of fatty meals. The parameters, including the fasting volume, residual volume, maximal gallbladder ejection fraction (EF) and EF at $30 \mathrm{~min}$ after the fatty meals were measured for analysis.

\section{Statistics}

The clinical data was analyzed by IBM SPSS v.20. All the values were expressed as mean $\pm \mathrm{SD}$ or frequency with percentage. Differences between two groups were analyzed, and two-tailed Student $t$ test was used for continuous data and chi-square test for categorical data. Univariate and multivariate Cox regression analyses were used to evaluate the factors affecting the recurrent biliary complications. $P<0.05$ was considered to be statistically significant.

\section{Results}

From August 2011 to December 2014, 1301 ERCP procedures were performed at Kaohsiung Veterans General Hospital. A total of 675 patients who were diagnosed as having CBDS based on their clinical symptoms, laboratory tests, and image studies, received endoscopic treatment to clear the bile duct. Of these 675 patients, 138 patients had previously received a cholecystectomy, and 537 had an intact gallbladder. One hundred and thirty patients initially agreed to join this study, but 12 were excluded. These include three patients with intrahepatic duct stones, seven refusals of subsequent follow-up, one with newly developed cancers within six months of follow-up, and one with recurring biliary complication before receiving gallbladder function test (Fig. 1).

Among the 118 patients, 76 were male and 42 patients were female. The mean age was $63.6 \pm 17.5$ years old. Thirty one patients had habitual smoking, and 18 patients had at least a drink per week. Concomitant diseases included chronic lung disease in seven patients, cerebrovascular disease in seven patients, cardiovascular disease in 53 patients, renal failure in seven patients, a history of cancer disease after remission or curative treatment in 12 patients, chronic liver disease in $12 \mathrm{pa}$ tients, and diabetes mellitus in 25 patients. 24 patients were acute biliary pancreatitis, but refused cholecystectomy after well explanation. Gallbladder stones were identified in 86 patients by an abdominal sonogram or a CT before endoscopic treatment. Forty-five patients had a juxtapapillary diverticulum. The mean common bile duct diameter was $1.2 \pm 0.4 \mathrm{~cm}$. Five patients received endoscopic sphincterotomy (EST), while 113 patients received EPBD to enlarge the papillary orifice. In the patients who received $\mathrm{EPBD}$, the mean diameter of the balloon was $1.1 \pm 0.2 \mathrm{~cm}$. Twelve patients received mechanical lithotripsy to retrieve stones. Twenty-three patients did not have gross stone retrieval after enlargement of the papillary orifice even though CBDS had been previously reviewed by other images. 51 of 95 extracted stones were brown pigment in type. The mean duration of the procedure was $49.2 \pm 22 \mathrm{~min}$. The procedures were successful in the first session for 110 patients. Four patients developed complications, including mild acute pancreatitis in three patients and fever with bacteremia after endoscopic

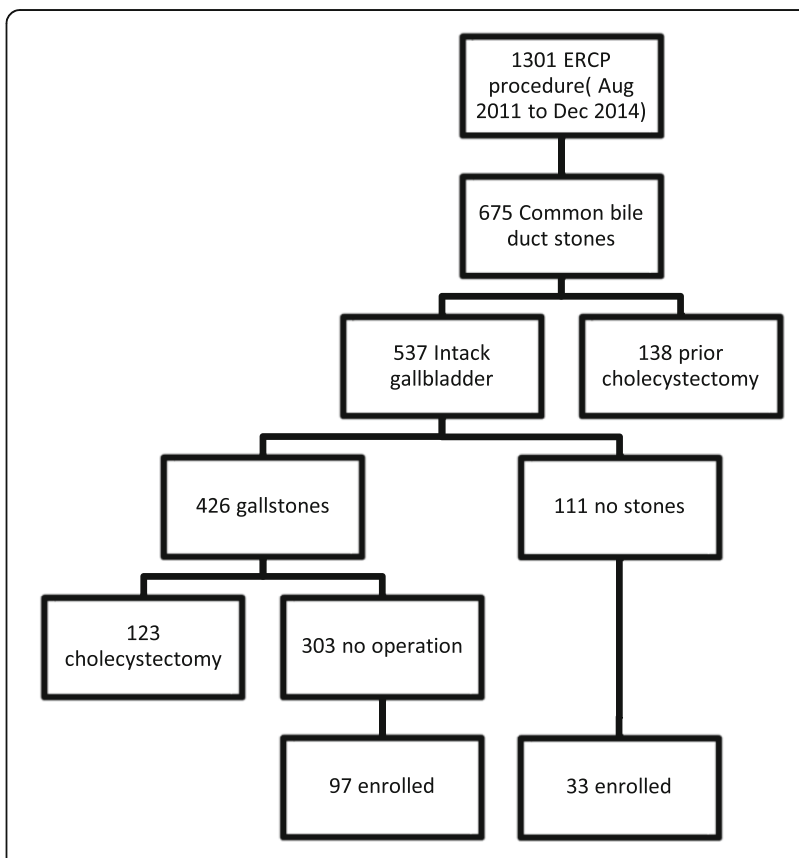

Fig. 1 Algorithm of patients enrolled to study 
treatment in one, and all patients recovered after conservative treatment for those complications.

Patients were followed for a median of 33 months (15-56 months). Recurrent biliary complications occurred in 23 patients (22 had GB stones and the other one without). Five patients suspected recurrent CBDS based on the symptoms and image findings at intervals of 12 to 31 months from the initial procedure. Two patients were confirmed to have stones and retrieved endoscopically; no gross stone was found during the endoscopic procedure in the other three patients. Two patients (one with gallbladder stones and the other without) developed acute cholangitis at eight and 28 months following the initial procedure and their symptoms subsided after conservative treatment. Ten patients developed acute cholecystitis at three to 28 months after initial endoscopic treatment. Although one of the ten patients had a ruptured gallbladder, he recovered smoothly after cholecystectomy. Six patients suffered from recurrent biliary pain at two to 22 months following initial endoscopic treatment, and four of them received elective cholecystectomy; all were well after their operation. Two patients with recurrent biliary pain refused elective cholecystectomy and were well after conservative treatment (Table 1).

Spontaneous clearance of stone from the gallbladder of 15 patients was confirmed by a subsequent abdominal sonogram at a median of 12 months (range one to 31 months) after endoscopic treatment. No common bile duct stones were detected in these 15 patients. Eight patients had a single gallbladder stone, and seven patients had multiple gallbladder stones. The mean size of the stones was $0.8 \pm 0.4 \mathrm{~cm}$ (range 0.2 to $1.8 \mathrm{~cm}$ ). Fifteen patients were symptom-free during the follow-up period. No new stone was found by sonography during the follow-up period in patients without stone in their gallbladder. FMS was successfully conducted in 110 patients, and failed in eight patients owing to either small contracted gallbladders filled with stones or gas blockages. One patient died of rectal cancer at 14 months following the endoscopic treatment; the other one patient was found to have lung cancer at seven months later and died at 22 months. Four patients died from renal failure, pneumonia, chronic hepatic failure, and heart failure, respectively.

Comparing with gallbladder stone, patients without it had a significantly higher incidence of chronic lung disease, a larger common bile duct diameter, larger stones, a higher incidence of the non-visualization of the gallbladder in ERCP, a larger mean diameter of the dilating balloon used, a higher frequency to use mechanical lithotripsy, and a larger percentage of gallbladder contraction of $>50 \%$ at $30 \mathrm{~min}$ after a fatty meal (Table 2).

According to the univariate Cox regression analysis, the presence of gallbladder stones, the drinking of alcohol,
Table 1 Patients' characteristics

\begin{tabular}{|c|c|}
\hline Parameter & Number (\%) \\
\hline Gender (male) & $76(64.4 \%)$ \\
\hline Age (mean $\pm S D)$ & $63.6 \pm 17.5$ years \\
\hline Smoking & $31(26.3 \%)$ \\
\hline Alcohol drinking & $18(15.3 \%)$ \\
\hline \multicolumn{2}{|l|}{ Concomitant disease } \\
\hline Chronic lung diseases & $7(5.9 \%)$ \\
\hline Cerebrovascular diseases & $7(5.9 \%)$ \\
\hline Cardiovascular diseases & $53(44.9 \%)$ \\
\hline Renal failure & $7(5.9 \%)$ \\
\hline Cancer diseases & $12(10.2 \%)$ \\
\hline Liver disease & $12(10.2 \%)$ \\
\hline Diabetes mellitus & $25(21.2 \%)$ \\
\hline Juxtapapillary diverticulum & $45(38.1 \%)$ \\
\hline Gallbladder stones & $86(72.9 \%)$ \\
\hline Biliary pancreatitis & $24(20.3 \%)$ \\
\hline CBD diameter (mean \pm SD) & $1.2 \pm 0.4 \mathrm{~cm}$ \\
\hline Number of CBD stones (no/single /multiple) & $23 / 59 / 36(20 / 50 / 30)$ \\
\hline Largest CBD stones size $(\text { mean } \pm \mathrm{SD})^{\mathrm{a}}$ & $0.9 \pm 0.4 \mathrm{~cm}$ \\
\hline Endoscopic procedures (EST/EPBD) & $5 / 113(4 / 96)$ \\
\hline Mean balloon diameter for EPBD (mean \pm SD) & $1.1 \pm 0.2 \mathrm{~cm}$ \\
\hline Mechanical lithotripsy & $12(10.2 \%)$ \\
\hline Sessions for bile duct clearance(> 1 session) & $8(6.8 \%)$ \\
\hline \multicolumn{2}{|l|}{ Stone color ${ }^{\mathrm{a}}$} \\
\hline Cholesterol and black pigment stones & $44(46 \%)$ \\
\hline Brown pigment stones & $51(54 \%)$ \\
\hline Mean ERCP procedure time (mean $\pm \mathrm{SD}$ ) & $49.2 \pm 22.2 \mathrm{~min}$ \\
\hline Postprocedural complications & $4(3.4 \%)$ \\
\hline Follow up time (median, range) months & 33 (15 to 56$)$ \\
\hline Recurrent biliary complications & $23(19.5 \%)$ \\
\hline Spontaneous passage of gallstones & $15(15 / 86=17.4 \%)$ \\
\hline Death during follow up & $6(5.1 \%)$ \\
\hline
\end{tabular}

CBD: common bile duct, EST: endoscopic sphincterotomy, EPBD: endoscopic papillary balloon dilation

${ }^{a} 23$ patients with stone pass-out were not included

renal failure, and more than one sessions of initial treatment for bile duct clearance significantly affect recurrent biliary complications $(P<0.05$, Table 3$)$. Moreover, the multivariate Cox regression analysis revealed that only the presence of gallbladder stones, the drinking of alcohol and more than one sessions of initial treatment for bile duct clearance are significantly associated with recurrent biliary complications $(P<0.05$, Table 4$)$. No significant differences existed between any of the parameters of gallbladder function by FMS between patients with different stone colors, patients with recurrent biliary complications, and patients who spontaneously passed their gallbladder stones. 
Table 2 Differences between the patients with and without gallstones

\begin{tabular}{|c|c|c|c|}
\hline & Gallbladder stones (+) & Gallbladder stones (-) & $P$ \\
\hline Gender (male/female) & $55 / 31$ & $21 / 11$ & 0.866 \\
\hline Age (mean $\pm S D$, years) & $62.5 \pm 17.9$ & $66.5 \pm 16.6$ & 0.276 \\
\hline Smoking (yes/no) & $19 / 67$ & $12 / 20$ & 0.091 \\
\hline Alcohol drinking (yes/no) & $13 / 73$ & $5 / 27$ & 0.946 \\
\hline \multicolumn{4}{|l|}{ Concomitant diseases } \\
\hline Chronic lung disease (yes/no) & $2 / 84$ & $5 / 27$ & 0.016 \\
\hline Cerebrovascular diseases (yes/no) & $4 / 82$ & $3 / 29$ & 0.387 \\
\hline Cardiovascular diseases (yes/no) & $37 / 49$ & $16 / 16$ & 0.016 \\
\hline Renal failure (yes/no) & $7 / 79$ & $0 / 32$ & 0.187 \\
\hline Cancer diseases (yes/no) & $10 / 76$ & $2 / 30$ & 0.509 \\
\hline Liver disease (yes/no) & $7 / 79$ & $5 / 27$ & 0.232 \\
\hline Diabetes mellitus (yes/no) & $15 / 71$ & $10 / 22$ & 0.103 \\
\hline JPD (yes/no) & $29 / 57$ & $16 / 16$ & 0.106 \\
\hline $\mathrm{CBD}$ diameter (mean $\pm \mathrm{SD}, \mathrm{cm})$ & $1.2 \pm 0.4$ & $1.4 \pm 0.4$ & 0.017 \\
\hline CBDS pass-out (yes/no) & $18 / 68$ & $5 / 27$ & 0.518 \\
\hline Brown pigment stones (yes/no) & $38 / 30$ & $13 / 14$ & 0.495 \\
\hline Largest CBDS size (mean $\pm \mathrm{SD}, \mathrm{cm})$ & $0.8 \pm 0.4$ & $1.0 \pm 0.5$ & 0.016 \\
\hline CBDS number (single/multiple) ${ }^{\mathrm{a}}$ & $43 / 25$ & $16 / 11$ & 0.719 \\
\hline Mean balloon diameter for EPBD $(\text { mean } \pm S D)^{b}$ & $1.0 \pm 0.2$ & $1.2 \pm 0.3$ & 0.002 \\
\hline Mechanical lithotripsy (yes/no) & $4 / 82$ & $8 / 24$ & 0.003 \\
\hline Sessions for bile duct clearance $(1 />1)$ & $80 / 6$ & $30 / 2$ & 1.000 \\
\hline Non-visualization of gallbladder in ERCP (yes/no) & $24 / 62$ & $19 / 13$ & 0.002 \\
\hline \multicolumn{4}{|l|}{ Fatty meal sonography ${ }^{a}$} \\
\hline Fasting volume(ml) & $20.4 \pm 18.8$ & $23.0 \pm 21.9$ & 0.557 \\
\hline Residual volume (ml) & $5.2 \pm 5.3$ & $6.0 \pm 11.8$ & 0.624 \\
\hline Ejection fraction (\%) & $48.9 \pm 36.0$ & $63.2 \pm 33.1$ & 0.070 \\
\hline Ejection fraction at $30 \mathrm{~min}(\geq 50 \%$ vs $<50 \%)$ & $39 / 44$ & $20 / 7$ & 0.014 \\
\hline
\end{tabular}

$J P D$ : juxtapapillary diverticulum, CBD: common bile duct, CBDS: common bile duct stone, EPBD: endoscopic papillary balloon dilation a 8 patients with small contracted gallbladder or gas block were excluded

${ }^{b}$ Only the 113 patients who received EPBD were included

\section{Discussions}

Reduced gallbladder motility is widely recognized as an important factor in the formation of cholesterol stones [22], but the role of the gallbladder function in the formation of pigment stones is controversial [23-25]. Brown stones form secondary to stasis and anaerobic bacterial infection in any part of the biliary tree including the gallbladder $[26,27]$. A higher percentage of our patients with calculus gallbladder than that of the acalculous gallbladder, had suboptimal gallbladder motility ( $53.3 \%$ vs. $25.9 \%)$, so gallbladder motility should be considered as a factor in the formation of gallbladder stone.

Following the endoscopic treatment of CBDS, recurrent biliary complication occurred in $3-21 \%$ of patients after EST [12] and in 5-25\% of patients after EPBD [28]. Calculus gallbladder was identified as one of the factors that is responsible for such complications [29]. EPLBD, using balloon $\geq 12 \mathrm{~mm}$, is a safe and effective method in facilitating the removal of CBDS as seen, but is not a sphincter-preserving procedure [30]. Sphincter-preserving methods such as EPBD, using the conventional $8 \mathrm{~mm}$ balloon should be suitable for patients with secondary CBDS that migrates from the gallbladder. EPLBD and a full EST can facilitate the biliary drainage of the bile duct and are suitable procedures for patients with primary CBDS or a prior cholecystectomy $[30,31]$. Although gallbladder motility improved only temporarily after endoscopic papillary dilation using a conventional $8 \mathrm{~mm}$ balloon [16, 32], improvement of gallbladder emptying and facilitation of the spontaneous passage of gallbladder stones after EST have been reported [14, 33]. In this study, even gallbladder ejection in patients with a calculus gallbladder was inferior to 
Table 3 Factors affecting the recurrent biliary complications (univariate analysis)

\begin{tabular}{|c|c|c|}
\hline Factors & Risk ratio $(95 \% \mathrm{Cl})$ & $P$ \\
\hline Gender (male/female) & $1.53(0.60-3.89)$ & 0.369 \\
\hline Mean age & $1.00(0.99-1.03)$ & 0.860 \\
\hline Smoking (yes/no) & $2.19(0.96-5.01)$ & 0.062 \\
\hline Alcohol drinking (yes/no) & $2.49(1.02-6.05)$ & 0.045 \\
\hline \multicolumn{3}{|l|}{ Concomitant diseases } \\
\hline Chronic lung disease (yes/no) & $1.70(0.40-7.27)$ & 0.473 \\
\hline Cerebrovascular diseases (yes/no) & $1.68(0.39-7.18)$ & 0.482 \\
\hline Renal failure (yes/no) & $3.19(1.09-9.39)$ & 0.035 \\
\hline Cancer diseases (yes/no) & $1.52(0.45-5.11)$ & 0.501 \\
\hline Liver disease (yes/no) & $2.35(0.79-6.98)$ & 0.123 \\
\hline Diabetes mellitus (yes/no) & $1.03(0.38-2.27)$ & 0.958 \\
\hline JPD (yes/no) & $1.05(0.45-2.42)$ & 0.888 \\
\hline Gallbladder stones(Yes/No) & $8.83(1.19-65.49)$ & 0.033 \\
\hline Mean CBD diameter & $2.26(0.83-6.180$ & 0.113 \\
\hline Mean balloon diameter for EPBD ${ }^{a}$ & $3.10(0.50-1900)$ & 0.222 \\
\hline Mechanical lithotripsy (yes/no) & $1.06(0.25-4.58)$ & 0.935 \\
\hline Brown pigment stones (yes/no) & $1.16(0.47-2.84)$ & 0.748 \\
\hline Sessions for bile duct clearance $(1 />1)$ & $0.32(0.11-0.93)$ & 0.037 \\
\hline Non-visualization of gallbladder in ERCP(yes/no) & $1.96(0.73-5.29)$ & 0.184 \\
\hline \multicolumn{3}{|l|}{ Fatty meal sonography ${ }^{b}$} \\
\hline Fasting volume & $1.01(0.99-1.03)$ & 0.596 \\
\hline Residual volume & $1.02(0.98-1.06)$ & 0.324 \\
\hline Ejection fraction & $1.00(0.99-1.01)$ & 0.986 \\
\hline Ejection fraction at $30 \mathrm{~min}(\geq 50 \%$ vs $<50 \%)$ & $0.70(0.31-1.59)$ & 0.400 \\
\hline
\end{tabular}

that in patients with an acalculous gallbladder, and $46.7 \%$ of the former maintained optimal gallbladder ejection. The presence of gallbladder stones rather than the gallbladder EF was the factor affected the late biliary complications in this study.

Non-filling of the gallbladder may be an indication for cholecystectomy $[34,35]$. Non-filling of the gallbladder may lead to failure of gallbladder contraction. However, bile stasis with subsequent sepsis and carcinoma is questionable, and no strong evidence supports the beneficial effect of cholecystectomy in patients with non-filling

Table 4 Multivariate analysis of the factors affecting recurrent biliary complications

\begin{tabular}{lll}
\hline Factors & Risk ratio $(95 \% \mathrm{Cl})$ & $P$ \\
\hline Gallstones (yes/no) & $8.42(1.12-63.14)$ & 0.038 \\
Alcohol drinking (yes/no) & $2.95(1.14-7.68)$ & 0.026 \\
Renal failure (yes/no) & $1.50(0.49-4.67)$ & 0.480 \\
Sessions for bile duct clearance (1/> 1) & $0.26(0.08-0.84)$ & 0.024 \\
\hline
\end{tabular}

gallbladder [7, 36, 37]. Although $8.4 \%$ (10/118) of patients developed acute cholecystitis (including one with gallbladder rupture) after endoscopic treatment for CBDS, all patients recovered completely after their operation. In addition, fifteen patients (12.7\%) were found to have been spontaneously passed their gallbladder stones in the follow-up period. Endoscopic treatment of the biliary sphincter by either EST or endoscopic sphincterotomy plus large balloon dilation (ESLBD) may increase the gallbladder motility, facilitating the spontaneous passing of gallstones and increasing the risk of recurrent biliary complications, particularly gallbladder complications [38]. Except in cases of gallbladder-related complications, elective cholecystectomy does not help to prevent recurrent CBDS or cholangitis [29, 39]. Other studies have shown that prior cholecystectomy may be a factor in causing the recurrent CBDS [12, 40, 41]. These contradictory results raise a question regarding who will benefit from elective cholecystectomy following endoscopic treatment for CBDS. Some studies claimed that 
prophylactic cholecystectomy is not required in patients with acalculous gallbladder following endoscopic clearance of the bile duct [29], but elective cholecystectomy in patients with calculus gallbladder following endoscopic treatment is recommended owing to the risk of subsequent recurrent biliary complications [42, 43]. However, most relevant studies that strongly recommend routine cholecystectomy neglect the evidence of the spontaneous clearance of the gallbladder following endoscopic treatment. Although a calculus gallbladder is identified as a significant risk factor for recurrent biliary complications in this study, the rate of acute cholecystitis as a late complication was $8.4 \%(10 / 118)$, whereas the rate of asymptomatic spontaneous clearance of gallbladder stones was $12.7 \%(15 / 118)$. All patients in the current study were regularly followed at our clinic and were alert for recurrent symptoms. As a result, the possible recurrent complications can be detected early and managed properly [44]. Therefore, the wait-and-see policy for the patients with simple gallbladder stones may also be applicable for the patients with concurrent gallbladder stones and CBDS following endoscopic treatment. Surgical intervention should be conducted only on patients with recurrent gallbladderrelated complications to prevent an unnecessary cholecystectomy, particularly for the aged patients and patients with a high likelihood of the spontaneous emptying of gallbladder stones, including those with small stones, a wide cystic duct, low or a small angle of cystic duct insertion with CBD [45-47].

FMS is a simple and accurate noninvasive test to determine gallbladder size and contraction $[20,48]$. A simple fatty meal can induce a neurocephalic and hormonal response, and it is more physiological than using cholecystokinin injection in testing the gallbladder emptying [49]. A large fasting or residual gallbladder volume, and a low ejection fraction at 30 or 45 min have been reported to be present in patients with calculus gallbladder [50-53]. The parameters of gallbladder motility may be influenced by body weight, age, sex, the patency of the cystic duct and the biliary tract, and the method of testing, so cutoff values have ranged from $35 \%$ to $80 \%$ in the literature [54,55]. 50\% is used as the cutoff value of GBEF at 30 min because our patients had previously received endoscopic treatment of the sphincter of Oddi. Although the incidence of abnormal GBEF at $30 \mathrm{~min}$ is significantly higher in calculus gallbladders than acalculous gallbladders, no variation existed in this respect among the patients with late biliary symptoms, patients with spontaneously passed gallbladder stones and patients who fell in neither group. Fifty four percent of extracted stones were brown pigment stones which were produced primarily in the bile duct. This fact also may explain failure to identify the relationship between gallbladder function and recurrent biliary complications in our patients. According to simultaneous fatty meal scintigraphy and sonography, the postprandial gallbladder can handle up to six times its basal volumes within a period of $90 \mathrm{~min}$ in healthy subjects, but the turnover of bile is markedly reduced in patients with a calculus gallbladder [56]. Since the gallbladder function is complex and cannot be reliably measured by FMS or scintigraphy alone to predict the symptoms or outcome of a cholecystectomy $[57,58]$, whether simultaneous scintigraphy and sonography is a better method than either requires further investigation to determine.

Along with a calculus gallbladder, the drinking of alcohol at least weekly and initial clearance of the bile duct with more than one session of endoscopic treatment affect recurrent biliary complications in this study. The effect of alcohol on the gallbladder and the biliary tract are controversial. Peoples who frequently consume alcohol are less likely to suffer from gallstones disease [59]. Alcohol has been found to inhibit activity of the sphincter of Oddi [60], alcohol may have affected the residual function of the sphincter of Oddi or emptying of the bile duct in our patients even following endoscopic treatment, resulting in delayed biliary emptying and biliary complications [11]. Incomplete clearance of the bile duct in one session significantly affects recurrent biliary complications, and most patients who required a secondlook procedure, usually had multiple or difficult stones. Some radiological undetected small stone fragments may have been left in the bile duct, and their migration may cause recurrent symptoms.

This study has some limitations. The follow-up time was not long enough to observe the rate of re-recurrent biliary complications in patients who had undergone a cholecystectomy. Most of the stones in our patients were mixed black and brown, so differentiating between secondary and primary bile duct stones was difficult. Our patients were acutely ill before endoscopic treatment, so no FMS was performed before endoscopic treatment for baseline reference. Owing to blockage by gas or stone, FMS was not successfully performed in all patients. A further long-term study is required to evaluate the clinical significance of gallbladder function and the effect of cholecystectomy in these patients.

\section{Conclusions}

Gallbladder ejection fraction was poorer in patients with gallbladder stones, but it could not predict further recurrent biliary complications. Alcohol restriction would probably help to reduce recurrent biliary symptoms. Since spontaneous clearance of gallbladder stone may occur, wait and see policy of gallbladder management after endoscopic treatment of CBDS is appropriate, but regular follow- up in those patients with risk factors for recurrence is necessary. 


\section{Cholecystectomy is warranted only in patients with recur- rent gallbladder-related symptoms.}

\section{Abbreviation}

CBD: common bile duct; CBDS: common bile duct stone; EF: ejection fraction; EPBD: endoscopic papillary balloon dilation; EPLBD: endoscopic papillary large balloon dilation; ERCP: endoscopic retrograde cholangiopancreatography; ESLBD: endoscopic sphincterotomy plus large balloon dilation; EST: Endoscopic sphincterotomy; FMS: fatty meal sonography; GBEF: gallbladder ejection fraction; MRCP: magnetic resonance cholangiopancreatography

\section{Acknowledgements}

The authors thank Miss Shu-Hung Shih for the help of clinical follow-up and data management.

\section{Funding}

The authors would like to thank the Ministry of Science and Technology (NSC100-2314-B075-004), and Kaohsiung Veterans General Hospital (VGHKS 102-012, VGHKS 103-102) of the Republic of China, Taiwan for financially supporting the research.

\section{Availability of data and materials}

The raw data generated or analyzed during this study are available from the first author (Tzung-Jiun Tsai, medfungi@yahoo.com.tw) on reasonable request.

\section{Authors' contributions}

$\mathrm{TJ}, \mathrm{KH}, \mathrm{HH}$ designed the study; TJ, CA performed and interpreted the fatty meal sonography; $\mathrm{KH}, \mathrm{HH}, \mathrm{TJ}, \mathrm{CA}, \mathrm{WC}, \mathrm{KH}$, IM performed the endoscopic treatment; WL, WC, HM, FW, JS, PI collected the patients and helped for data analysis; HS performed the statistics of data; $\mathrm{TJ}, \mathrm{HH}$ and $\mathrm{KH}$ prepared the manuscript. All authors read and approved the final manuscript.

\section{Ethics approval and consent to participate}

This study was approved by the Institutional Review Board of Kaohsiung Veterans General Hospital (VGHKS-CT6-05) and was performed according to the Helsinski Declaration. The protocol was registered in the Government Research Bulletin according to the law of Taiwan. Both written and verbal informed consent was obtained for all participants.

\section{Consent for publication}

Not applicable

\section{Competing interests}

The authors declare that they have no competing interests.

\section{Publisher's Note}

Springer Nature remains neutral with regard to jurisdictional claims in published maps and institutional affiliations.

\section{Author details}

'Division of Gastroenterology and Hepatology, Department of Internal Medicine, Kaohsiung Veterans General Hospital, Kaohsiung, Taiwan, Republic of China. ${ }^{2}$ School of Medicine, National Yang-Ming University, Taipei, Taiwan, Republic of China. ${ }^{3}$ Department of Health-Business Administration, Fooyin University, Kaohsiung, Taiwan, Republic of China. ${ }^{4}$ Department of Biological Sciences, National Sun Yat-sen University, Kaohsiung, Taiwan, Republic of China. ${ }^{5}$ Department of Business Management, National Sun Yat-sen University, Kaohsiung, Taiwan, Republic of China. ${ }^{6}$ College of Pharmacy and Health Care, Tajen University, Pingtung city, Taiwan, Republic of China.

Received: 5 January 2017 Accepted: 22 February 2018

Published online: 27 February 2018

\section{References}

1. Bergman JJ, Rauws EA, Fockens P, van Berkel AM, Bossuyt PM, Tijssen JG, Tytgat GN, Huibregtse K. Randomised trial of endoscopic balloon dilation versus endoscopic sphincterotomy for removal of bileduct stones. Lancet. 1997;349(9059):1124-9.
2. Lin CK, Lai KH, Chan HH, Tsai WL, Wang EM, Wei MC, Fu MT, Lo CC, Hsu PI, Lo GH. Endoscopic balloon dilatation is a safe method in the management of common bile duct stones. Dig Liver Dis. 2004;36(1):68-72.

3. Rosch W, Riemann JF, Lux G, Lindner HG. Long-term follow-up after endoscopic sphincterotomy. Endoscopy. 1981;13(4):152-3.

4. Tanaka M, Ikeda S, Yoshimoto $\mathrm{H}$, Matsumoto $\mathrm{S}$. The long-term fate of the gallbladder after endoscopic sphincterotomy. Complete follow-up study of 122 patients. Am J Surg. 1987;154(5):505-9.

5. Lau JY, Leow CK, Fung TM, Suen BY, Yu LM, Lai PB, Lam YH, Ng EK, Lau WY, Chung SS, et al. Cholecystectomy or gallbladder in situ after endoscopic sphincterotomy and bile duct stone removal in Chinese patients. Gastroenterology. 2006;130(1):96-103.

6. Martin DF, Tweedle DE. Endoscopic management of common duct stones without cholecystectomy. Br J Surg. 1987;74(3):209-11.

7. Lai KH, Lin LF, Lo GH, Cheng JS, Huang RL, Lin CK, Huang JS, Hsu PI, Peng NJ, Ger LP. Does cholecystectomy after endoscopic sphincterotomy prevent the recurrence of biliary complications? Gastrointest Endosc. 1999:49(4 Pt 1):483-7.

8. Saito M, Tsuyuguchi T, Yamaguchi T, Ishihara T, Saisho H. Long-term outcome of endoscopic papillotomy for choledocholithiasis with cholecystolithiasis. Gastrointest Endosc. 2000;51(5):540-5.

9. Tsujino $T$, Kawabe $T$, Komatsu Y, Yoshida H, Isayama H, Sasaki T, Kogure H, Togawa O, Arizumi T, Matsubara S, et al. Endoscopic papillary balloon dilation for bile duct stone: immediate and long-term outcomes in 1000 patients. Clin Gastroenterol Hepatol. 2007;5(1):130-7.

10. Tsai TJ, Lai KH, Lin CK, Chan HH, Wang EM, Tsai WL, Cheng JS, Yu HC, Chen WC, Hsu PI. The relationship between gallbladder status and recurrent biliary complications in patients with choledocholithiasis following endoscopic treatment. J Chin Med Assoc. 2012;75(11):560-6.

11. Lai KH, Peng NJ, Lo GH, Cheng JS, Huang RL, Lin CK, Huang JS, Chiang HT, Ger LP. Prediction of recurrent choledocholithiasis by quantitative cholescintigraphy in patients after endoscopic sphincterotomy. Gut. 1997; 41(3):399-403.

12. Ando T, Tsuyuguchi T, Okugawa T, Saito M, Ishihara T, Yamaguchi T, Saisho H. Risk factors for recurrent bile duct stones after endoscopic papillotomy. Gut. 2003;52(1):116-21

13. Cerci SS, Ozbek FM, Cerci C, Baykal B, Eroglu HE, Baykal Z, Yildiz M, Saglam $S$, Yesildag A. Gallbladder function and dynamics of bile flow in asymptomatic gallstone disease. World J Gastroenterol. 2009:15(22):2763-7.

14. Dhiman RK, Phanish MK, Chawla YK, Dilawari JB. Gallbladder motility and lithogenicity of bile in patients with choledocholithiasis after endoscopic sphincterotomy. J Hepatol. 1997;26(6):1300-5.

15. Sharma BC, Agarwal DK, Baijal SS, Negi TS, Choudhuri G, Saraswat VA. Effect of endoscopic sphincterotomy on gall bladder bile lithogenicity and motility. Gut. 1998;42(2):288-92.

16. Sugiyama M, Atomi Y. Long-term effects of endoscopic papillary balloon dilation on gallbladder motility. Dig Dis Sci. 2004;49(11-12):1803-7.

17. Chan HH, Lai KH, Lin CK, Tsai WL, Wang EM, Hsu PI, Chen WC, Yu HC, Wang HM, Tsay FW, et al. Endoscopic papillary large balloon dilation alone without sphincterotomy for the treatment of large common bile duct stones. BMC Gastroenterol. 2011;11:69.

18. Gracie WA, Ransohoff DF. The natural history of silent gallstones. N Engl J Med. 1982;307(13):798-800.

19. Tsai WL, Lai KH, Lin CK, Chan HH, Lo CC, Hsu PI, Chen WC, Cheng JS, Lo GH. Composition of common bile duct stones in Chinese patients during and after endoscopic sphincterotomy. World J Gastroenterol. 2005:11(27):4246-9.

20. Dodds WJ, Groh WJ, Darweesh RM, Lawson TL, Kishk SM, Kern MK. Sonographic measurement of gallbladder volume. AJR Am J Roentgenol. 1985;145(5):1009-11.

21. Lai KH, Peng NJ, Lo GH, Lin CK, Chan HH, Hsu PI, Cheng JS, Wang YY. Does a fatty meal improve hepatic clearance in patients after endoscopic sphincterotomy? J Gastroenterol Hepatol. 2002;17(3):337-41.

22. Johnston DE, Kaplan MM. Pathogenesis and treatment of gallstones. N Engl J Med. 1993;328(6):412-21.

23. Behar J, Lee KY, Thompson WR, Biancani P. Gallbladder contraction in patients with pigment and cholesterol stones. Gastroenterology. 1989;97(6): 1479-84.

24. Portincasa P, Moschetta A, Berardino M, Di-Ciaula A, Vacca M, Baldassarre G, Pietrapertosa A, Cammarota R, Tannoia N, Palasciano G. Impaired gallbladder motility and delayed orocecal transit contribute to pigment gallstone and biliary sludge formation in beta-thalassemia major adults. World J Gastroenterol. 2004;10(16):2383-90. 
25. Portincasa P, Di Ciaula A, Vendemiale G, Palmieri V, Moschetta A, VanbergeHenegouwen GP, Palasciano G. Gallbladder motility and cholesterol crystallization in bile from patients with pigment and cholesterol gallstones. Eur J Clin Investig. 2000;30(4):317-24.

26. Vitek L, Carey MC. New pathophysiological concepts underlying pathogenesis of pigment gallstones. Clin Res Hepatol Gastroenterol. 2012;36(2):122-9.

27. O'Donnell LJ, Fairclough PD. Gall stones and gall bladder motility. Gut. 1993;34(4):440-3.

28. Chung JW, Chung JB. Endoscopic papillary balloon dilation for removal of choledocholithiasis: indications, advantages, complications, and long-term follow-up results. Gut and liver. 2011;5(1):1-14.

29. Kim MH, Yeo SJ, Jung MK, Cho CM. The Impact of Gallbladder Status on Biliary Complications After the Endoscopic Removal of Choledocholithiasis. Dig Dis Sci. 2016;61(4):1165-71.

30. Lai KH, Chan HH, Tsai TJ, Cheng JS, Hsu PI. Reappraisal of endoscopic papillary balloon dilation for the management of common bile duct stones. World J Gastrointest Endosc. 2015;7(2):77-86.

31. Kim IS, Myung SJ, Lee SS, Lee SK, Kim MH. Classification and nomenclature of gallstones revisited. Yonsei Med J. 2003;44(4):561-70.

32. Sugiyama $M$, Atomi $Y$. Does endoscopic papillary balloon dilation affect gallbladder motility? Gastrointest Endosc. 1999;50(1):74-8.

33. Hutton SW, Sievert CE Jr, Vennes JA, Shafer RB, Duane WC. Spontaneous passage of glass beads from the canine gallbladder: facilitation by sphincterotomy. Gastroenterology. 1988;94(4):1031-5.

34. Desa LA, Grace PA, Vipond MN, Henderson B, Thompson JN. Gall bladder function after endoscopic sphincterotomy. BMJ (Clin Res ed). 1990; 300(6732):1111.

35. Worthley CS, Toouli J. Gallbladder non-filling: an indication for cholecystectomy after endoscopic sphincterotomy. Br J Surg. 1988;75(8):796-8.

36. Horton R, L A. Gall bladder function after endoscopic sphincterotomy. BM (Clin Res ed). 1990;300(6739):1584-5.

37. Arnold JD, Wilkins WE. Gall bladder function after endoscopic sphincterotomy. BMJ (Clin Res ed). 1990;300(6739):1584-5.

38. Hansell DT, Millar MA, Murray WR, Gray GR, Gillespie G. Endoscopic sphincterotomy for bile duct stones in patients with intact gallbladders. Br J Surg. 1989;76(8):856-8

39. Heo J, Jung MK, Cho CM. Should prophylactic cholecystectomy be performed in patients with concomitant gallstones after endoscopic sphincterotomy for bile duct stones? Surg Endosc. 2015;29(6):1574-9.

40. Ohashi A, Tamada K, Wada S, Hatanaka H, Tomiyama T, Tano S, Nakazawa K, Sugano K. Risk factors for recurrent bile duct stones after endoscopic papillary balloon dilation: long-term follow-up study. Dig Endosc. 2009;21(2):73-7.

41. Wu SD, Tian Y, Kong J, Ding RY, Jin JZ, Guo RX. Possible relationship between cholecystectomy and subsequent occurrence of primary common bile duct stones: a retrospective review of data. Hepatobiliary Pancreat Dis Int. 2007;6(6):627-30.

42. Zargar SA, Mushtaq M, Beg MA, Javaid G, Khan BA, Hassan R, Kasana RA, Tabassum S. Wait-and-see policy versus cholecystectomy after endoscopic sphincterotomy for bile-duct stones in high-risk patients with co-existing gallbladder stones: a prospective randomised trial. Arab J Gastroenterol. 2014;15(1):24-6.

43. Cheng CT, Yeh CN: Effects of cholecystectomy on recurrent biliary complications after endoscopic treatment of common bile duct stone: a population-based cohort study. 2017

44. Lai KH, Lo GH, Lin CK, Hsu PI, Chan HH, Cheng JS, Wang EM. Do patients with recurrent choledocholithiasis after endoscopic sphincterotomy benefit from regular follow-up? Gastrointest Endosc. 2002;55(4):523-6.

45. Sharma BC, Agarwal DK, Baijal SS, Saraswat VA. Spontaneous passage of gallbladder calculi-facilitation by endoscopic sphincterotomy. HPB Surg. 1998;11(1):23-6

46. Williams EJ, Green J, Beckingham I, Parks R, Martin D, Lombard M. Guidelines on the management of common bile duct stones (CBDS). Gut. 2008;57(7):1004-21.

47. Yasui T, Takahata S, Kono H, Nagayoshi Y, Mori Y, Tsutsumi K, Sadakari Y, Ohtsuka T, Nakamura M, Tanaka M. Is cholecystectomy necessary after endoscopic treatment of bile duct stones in patients older than 80 years of age? J Gastroenterol. 2012;47(1):65-70.

48. Everson GT, Braverman DZ, Johnson ML, Kern F Jr. A critical evaluation of real-time ultrasonography for the study of gallbladder volume and contraction. Gastroenterology. 1980;79(1):40-6.
49. Fullarton GM, Meek AC, Gray HW, Bessent RG. Gallbladder emptying following cholecystokinin and fatty meal in normal subjects. HepatoGastroenterology. 1990;37(Suppl 2):45-8.

50. Palasciano G, Serio G, Portincasa P, Palmieri V, Fanelli M, Velardi A, Calo' Gabrieli B, Vinciguerra V. Gallbladder volume in adults, and relationship to age, sex, body mass index, and gallstones: a sonographic population study. Am J Gastroenterol. 1992;87(4):493-7.

51. Kishk SM, Darweesh RM, Dodds WJ, Lawson TL, Stewart ET, Kern MK, Hassanein EH. Sonographic evaluation of resting gallbladder volume and postprandial emptying in patients with gallstones. AJR Am J Roentgenol. 1987:148(5):875-9.

52. Pauletzki J, Cicala M, Holl J, Sauerbruch T, Schafmayer A, Paumgartner G. Correlation between gall bladder fasting volume and postprandial emptying in patients with gall stones and healthy controls. Gut. 1993;34(10):1443-7.

53. van Erpecum KJ, van Berge Henegouwen GP, Stolk MF, Hopman WP, Jansen JB, Lamers CB. Fasting gallbladder volume, postprandial emptying and cholecystokinin release in gallstone patients and normal subjects. J Hepatol. 1992;14(2-3):194-202

54. Goussous N, Kowdley GC, Sardana N, Spiegler E, Cunningham SC. Gallbladder dysfunction: how much longer will it be controversial? Digestion. 2014;90(3):147-54.

55. Lanzini A, Lanzarotto F, Baisini O, Amato M, Benini F. Value of measuring gallbladder motility in clinical practice. Dig Liver Dis. 2003;35(Suppl 3):S46-50,

56. Jazrawi RP, Pazzi P, Petroni ML, Prandini N, Paul C, Adam JA, Gullini S, Northfield TC. Postprandial gallbladder motor function: refilling and turnover of bile in health and in cholelithiasis. Gastroenterology. 1995:109(2):582-91.

57. Larsen TK, Qvist N. The influence of gallbladder function on the symptomatology in gallstone patients, and the outcome after cholecystectomy or expectancy. Dig Dis Sci. 2007;52(3):760-3.

58. DiBaise JK, Oleynikov D. Does gallbladder ejection fraction predict outcome after cholecystectomy for suspected chronic acalculous gallbladder dysfunction? A systematic review. Am J Gastroenterol. 2003;98(12):2605-11.

59. Walcher T, Haenle MM, Mason RA, Koenig W, Imhof A, Kratzer W. The effect of alcohol, tobacco and caffeine consumption and vegetarian diet on gallstone prevalence. Eur J Gastroenterol Hepatol. 2010;22(11):1345-51.

60. Tierney S, Qian Z, Lipsett PA, Pitt HA, Lillemoe KD. Ethanol inhibits sphincter of Oddi motility. J Gastrointest Surg. 1998:2(4):356-62.

\section{Submit your next manuscript to BioMed Central and we will help you at every step:}

- We accept pre-submission inquiries

- Our selector tool helps you to find the most relevant journal

- We provide round the clock customer support

- Convenient online submission

- Thorough peer review

- Inclusion in PubMed and all major indexing services

- Maximum visibility for your research

Submit your manuscript at www.biomedcentral.com/submit
) Biomed Central 